\title{
TECNOLOGIAS ASSISTIVAS NO ENSINO E APRENDIZAGEM DE MATEMÁTICA PARA ESTUDANTE CEGO: INVESTIGANDO A PRESENÇA DO DESENHO UNIVERSAL E DO DESENHO UNIVERSAL PARA APRENDIZAGEM
}

\author{
TECNOLOGÍAS DE ASISTENCIA EN LA ENSEÑANZA Y EL APRENDIZAJE DE LAS \\ MATEMATICAS PARA ESTUDIANTE CIEGO: INVESTIGANDO LA PRESENCIA \\ DEL DISEÑO UNIVERSAL Y EL DISEÑO UNIVERSAL PARA EL APRENDIZAJE
}

\section{ASSISTIVE TECHNOLOGIES IN TEACHING AND LEARNING MATHEMATICS FOR BLIND STUDENTS: INVESTIGATING THE PRESENCE OF UNIVERSAL DESIGN AND UNIVERSAL DESIGN FOR LEARNING}

Sandra Maria Ferreira JEREMIAS ${ }^{1}$

Anderson Roges Teixeira GÓES ${ }^{2}$ Sonia Maria Chaves HARACEMIV ${ }^{3}$

RESUMO: O presente artigo apresenta análises de pesquisas stricto sensu que abordam as tecnologias assistivas no ensino e aprendizagem de matemática voltada ao estudante cego. Com isso, verifica-se se esses recursos são concebidos na perspectiva do Desenho Universal (DU) e, ainda, se as metodologias indicadas nas pesquisas possuem abordagem do Desenho Universal para Aprendizagem (DUA). A metodologia da pesquisa é de natureza qualitativa, constituindo-se como revisão sistemática e integrativa em diferentes locais de buscas, como o Catálogo de Teses e Dissertações da Coordenação de Aperfeiçoamento de Pessoal de Nível Superior (CAPES). Os resultados demonstram a existência de poucas pesquisas na abordagem DUA. No entanto, as práticas que fazem uso do DUA possibilitam ao estudante cego a participação efetiva, com equidade, nos processos educacionais inclusivos no ambiente de sala de aula.

PALAVRAS-CHAVE: Ensino da matemática. Desenho universal para aprendizagem. Estudante cego.

RESUMEN: Este artículo presenta análisis de investigaciones stricto sensu que abordan las tecnologías de asistencia en la enseñanza y el aprendizaje de las matemáticas dirigidas a estudiantes ciegos. Con eso, se verifica si estos recursos se conciben en la perspectiva del Diseño Universal (DU) y, aún, si las metodologías señaladas en la investigación tienen

\footnotetext{
${ }^{1}$ Secretaria de Estado da Educação (SEED), São José dos Pinhais - PR - Brasil. Professora da sala de recursos. Mestranda do Programa de Pós-Graduação em Educação: Teoria e Prática de Ensino (PPGE-TPEn/UFPR). ORCID: https://orcid.org/0000-0001-9066-1934. E-mail: sandra.jeremias@escola.pr. gov.br

${ }^{2}$ Universidade Federal do Paraná (UFPR), Curitiba - PR - Brasil. Professor do Programa de Pós-Graduação em Educação: Teoria e Prática de Ensino (PPGE-TPEn) e do Programa de Pós-graduação em Educação em Ciências e em Matemática (PPGECM). Doutorado em Métodos Numéricos em Engenharia (UFPR). ORCID: https://orcid.org/0000-0001-8572-3758.E-mail: artgoes@ufpr.br

${ }^{3}$ Universidade Federal do Paraná (UFPR), Curitiba - PR - Brasil. Professora do Programa de Pós-Graduação em Educação: Teoria e Prática de Ensino (PPGE-TPEn) e do Programa de Pós-Graduação em Educação (PPGE). Doutorado em História e Filosofia da Educação (PUC/SP). ORCID: https://orcid.org/0000-0001-9305-5227. Email: sharacemiv@gmail.com
}

RIAEE - Revista Ibero-Americana de Estudos em Educação, Araraquara, v. 16, n. esp. 4, p. 3005-3019, dez. 2021. e-ISSN: 1982-5587 
enfoque de Diseño Universal de Aprendizaje (DUA). La metodología de investigación es de carácter cualitativo, siendo una investigación de revisión sistemática e integradora en diferentes ubicaciones de búsqueda, como el Catálogo de Tesis y Disertaciones de la Coordinación para el Perfeccionamiento del Personal de Educación Superior (CAPES). Los resultados demuestran que hay poca investigación sobre el enfoque DUA. Pero las practicas que hacen uso de la perspectiva DUA permite a los estudiantes ciegos participar de manera efectiva, con equidad, en procesos educativos inclusivos en el ambiente del aula.

PALABRAS CLAVE: Enseñanza de las matemáticas. Diseño universal de aprendizaje. Estudiante ciego.

ABSTRACT: This article presents analyzes of stricto sensu researches that address assistive technologies in the teaching and learning of mathematics aimed at blind students. With that, it is verified if these resources are conceived in the perspective of Universal Design (DU) and, still, if the methodologies indicated in the research have approach of Universal Design for Learning (DUA). The research methodology is of a qualitative nature, being a systematic and integrative review research of the findings in different search sites, such as the Catalog of Theses and Dissertations of the Coordination for the Improvement of Higher Education Personnel (CAPES). The results demonstrate little amount of research in the DUA perspective. However, the practices that make use of the DUA enables blind students to effectively participate, with equity, in inclusive educational processes in the classroom environment.

KEYWORDS: Mathematics teaching. Universal design for learning. Blind student.

\section{Introdução}

A inclusão escolar é discussão de importantes eventos, sendo o de maior visibilidade o ocorrido em 1994, na Espanha, promovido pela UNESCO, a Conferência Mundial sobre Necessidades Educativas Especiais: Acesso e qualidade. Na ocasião foi firmado por diversos países, dentre eles o Brasil, um dos mais importantes documentos, a Declaração de Salamanca (UNESCO, 2004), reafirmando o direito à educação de cada indivíduo, estabelecendo princípios, política e prática em Educação Especial. A Declaração de Salamanca ainda recomenda a inclusão de crianças e jovens com necessidades educacionais especiais nas escolas comuns, trazendo a discussão do conceito de escola inclusiva, desafiando o desenvolvimento de uma pedagogia que respeite as diferenças individuais, quebrando barreiras que tornam os estudantes incapazes momentaneamente.

Em relação às barreiras que impedem a real inclusão dos estudantes no ambiente escolar, não nos referindo apenas às barreiras descritas na lei 13.146 de 2015, Lei Brasileira de Inclusão da Pessoa com Deficiência ou Estatuto da Pessoa com Deficiência, mas sim aos recursos, serviços e/ou metodologias que abranjam todos os estudantes e proporcionem um 
processo de ensino e aprendizagem com equidade. $\mathrm{O}$ fato dos estudantes estarem matriculados em uma instituição escolar dita "regular" não necessariamente garante a inclusão educacional, pois é necessária a adoção de recursos de ensino e equipamentos especializados que atendam às necessidades educacionais dos estudantes, com ou sem deficiências (MANTOAN, 2003, p. 24), como garantidos na legislação brasileira,

III - projeto pedagógico que institucionalize o atendimento educacional especializado, assim como os demais serviços e adaptações razoáveis, para atender às características dos estudantes com deficiência e garantir o seu pleno acesso ao currículo em condições de igualdade, promovendo a conquista e o exercício de sua autonomia (BRASIL, 2015, Art. 28).

A inclusão escolar não prevê a utilização de práticas de ensino para atender às dificuldades de aprendizagem específicas, uma vez que compreende que "Os alunos aprendem nos seus limites e se o ensino for, de fato, de boa qualidade, o professor levará em conta esses limites ao explorar convenientemente as possibilidades de cada um" (MANTOAN, 2003, p. 36). Assim, quando se pensa na diversidade que compõe a escola, deve-se ter currículo que possa atender a todos de maneira igualitária por meio de diferentes percursos, com metas a serem atingidas por todos os estudantes.

Nessa perspectiva, o objetivo deste texto é analisar pesquisas stricto sensu que apresentam tecnologias assistivas ${ }^{4}$ para o ensino e aprendizagem de matemática, utilizadas por estudantes cegos. Com isso, procuramos verificar se esses recursos estão concebidos na perspectiva do Desenho Universal (DU) e, ainda, se as metodologias indicadas nas pesquisas possuem abordagem do Desenho Universal para Aprendizagem (DUA).

Desta forma, para fundamentar as discussões das análises, neste artigo, apresentamos, a seguir, as concepções do Desenho Universal e Desenho Universal para Aprendizagem.

\section{Desenho Universal para Aprendizagem}

O termo Desenho Universal (do inglês, Universal Design) foi idealizado pelo arquiteto Ron Mace nos anos 1980, nos Estados Unidos, para designar as diretrizes para projetos arquitetônicos e produtos que atendam todas as pessoas, independentemente de suas condições físicas. O DU possui sete princípios que buscam quebrar as barreiras (GABRILLI, 2007): igualitário; adaptável; óbvio; perceptível; seguro; sem esforço; e abrangente.

${ }^{4}$ III - tecnologia assistiva ou ajuda técnica: produtos, equipamentos, dispositivos, recursos, metodologias, estratégias, práticas e serviços que objetivem promover a funcionalidade, relacionada à atividade e à participação da pessoa com deficiência ou com mobilidade reduzida, visando à sua autonomia, independência, qualidade de vida e inclusão social; (BRASIL, 2015, Art. $3^{\circ}$ ). 
Quanto ao uso igualitário ou uso equiparável - "são espaços, objetos e produtos que podem ser utilizados por pessoas com diferentes capacidades, tornando os ambientes iguais para todos" (GABRILLI, 2007, p. 12) -, como exemplo, "Portas com sensores que se abrem sem exigir força física ou alcance das mãos de usuários de alturas variadas” (GABRILLI, 2007, p. 12).

O uso adaptável remete aos aspectos que podem alterar sua forma ou são concebidos para atender a todos, como uma tesoura para uso tanto de destros como canhotos ou computador com teclado e mouse, que auxiliam uma pessoa deficiente visual a fazer o uso de microcomputadores por meio do uso de sintetizador de voz (GABRILLI, 2007).

Em relação ao uso óbvio, definido também como simples e intuitivo, é considerado aspecto que se reconhece facilmente de maneira clara, "independente de sua experiência, conhecimento, habilidades de linguagem, ou nível de concentração" (GABRILLI, 2007, p. 14). Como exemplo, placas indicativas de sanitário feminino ou sanitário masculino para uso de pessoas com deficiência.

As informações facilmente perceptíveis estão relacionadas à ideia de quando uma informação é transmitida de forma a atender as necessidades do receptor. Gabrilli (2007) ilustra tal princípio mencionando diferentes meios de comunicação, tais como símbolos e letras em relevo, Braille, sinalização auditiva, entre outras.

O princípio seguro considerada a previsão para minimizar os riscos e as possíveis consequências de ações acidentais ou não intencionais, como elevadores com sensores em diversas alturas que permitam às pessoas com estaturas diferentes de fazerem uso sem riscos de a porta ser fechada quando estiverem entrando ou saindo do elevador. Já o princípio sem esforço está relacionado a não necessidade de minimização de esforço para manipulação, como as torneiras com sensor que não exige a torção no seu manuseio, o que propicia tanto a economia da água como também do esforço físico (GABRILLI, 2007).

O último princípio do DU, denominado de abrangente, traz a ideia de dimensionar o espaço para aproximação e uso, avaliando a extensão apropriada para o acesso, manipulação independentemente do tamanho do corpo, postura ou mobilidade do usuário, como poltronas que podem ser utilizadas por pessoas obesas (GABRILLI, 2007, p. 17).

Pensando no elemento arquitetônico que traga em sua concepção os princípios do DU, destacamos as rampas de acessos a diferentes níveis de alturas. Por meio deste elemento arquitetônico, pessoas com locomoção limitada podem acessar níveis superiores, assim como uma pessoa que não possui limitações em sua locomoção, trazendo acessibilidade de forma eficaz. 
No ambiente escolar, além do espaço físico, indicamos que os princípios do DU sejam aplicados aos recursos educacionais e esses, por sua vez, devem ser utilizados em metodologias que contemplem todos os estudantes.

As metodologias e práticas educacionais que contemplam todos os estudantes compõem a abordagem denominada de Desenho Universal para Aprendizagem (DUA) (do inglês, Universal Design for Learning), desenvolvida por David Rose, Anne Meyer e outros pesquisadores no Center for Applied Special Technology (CAST), na década de 1990, em Massachusetts. O DUA possui três princípios:

Princípio I - Fornecer múltiplos meios de engajamento que abarcam a autorregulação, a persistência e o esforço e o recrutamento do interesse. Sebastian-Heredero (2020) afirma que a aprendizagem está interligada às emoções das pessoas e à afetividade, a partir disso, os estudantes diferem notoriamente nos modos nos quais podem ser provocados e motivados para aprender. Alguns estudantes se mostram interessados e curiosos, enquanto outros demonstram desinteresse e resistência em participar de atividades desafiadoras, preferindo mais atividades rotineiras, optando por trabalhar sozinhos, ao invés de trabalhar coletivamente. Tais fatos demonstram que não há uma forma única para trabalhar com todos os alunos, sendo necessário desenvolver múltiplos modos.

Princípio II - Fornecer múltiplos meios de representação, envolvendo a percepção, linguagem, expressão e a compreensão de símbolos, por exemplo, matemáticos. Alguns estudantes aprendem de forma mais rápida, outros aprendem de maneira mais eficaz por meio de recursos visuais ou auditivos, em vez de um texto impresso. Assim, quanto mais oportunidades de aprendizagem forem utilizadas, maiores serão as possibilidades dos estudantes fazerem conexões interiores, como entre os conceitos (SEBASTIAN-HEREDERO, 2020).

Princípio III - Fornecer múltiplos meios de ação e expressão para abranger a função executiva, expressão e comunicação e atividade física. Sebastian-Heredero (2020) adverte sobre a necessidade do reconhecimento das especificidades de aprendizagens, ressaltando que alguns estudantes se expressam a partir de um texto escrito e outros de forma oral, o que denota diferentes processos nas formas como concebem o conhecimento e, assim, expressam o que sabem. Constata-se, a partir disso, a necessidade de desenvolver diferentes estratégias para a apreensão dos conteúdos.

Os princípios do DUA são divididos em diretrizes que possuem pontos de verificação com sugestões mais detalhadas, apresentadas na Figura 1, sendo base para o estabelecimento 
de metas de aprendizagem, aplicadas a partir do recrutamento de interesses, percepção e ação física, com vista a atingir as metas de aprendizagem.

Figura 1 - Princípio e diretrizes do DUA

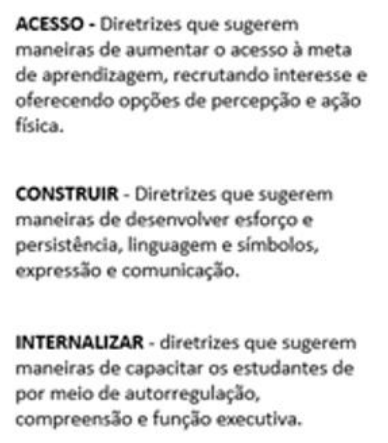

Objetivo: estudantes especialistas que são...
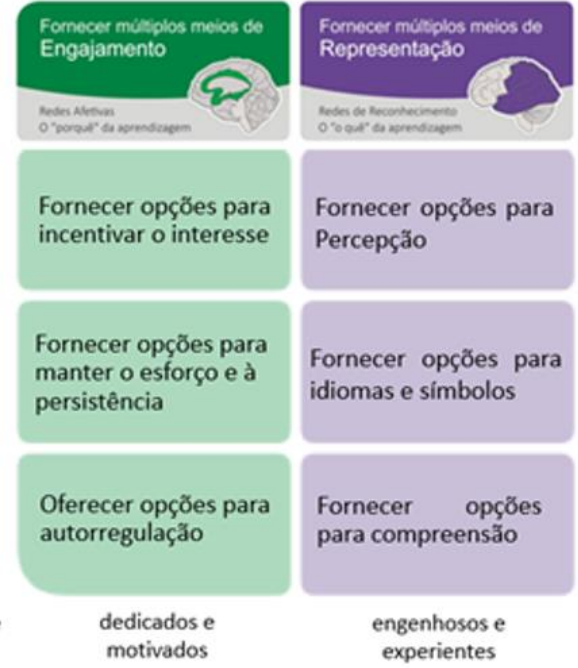

Fonte: adaptado e traduzido de CAST (2019)

Para tanto é necessário que o professor dedique esforço para recrutar a atenção e o envolvimento dos estudantes, utilizando outras diversas formas e recursos na construção da aprendizagem, seja por meio da utilização da linguagem, símbolos, expressão e outros, possibilitando aos estudantes desempenharem as tarefas propostas com autonomia mediante as situações.

Compreendidas as concepções sobre DU e DUA, na próxima seção, apresenta-se a metodologia da pesquisa, indicando como e quais foram as pesquisas selecionadas para a análise.

\section{Metodologia da Pesquisa}

A pesquisa é de natureza qualitativa, com revisão sistemática e integrativa, buscando produções científicas sobre o tema, analisando as pesquisas stricto sensu que tratam de tecnologias assistivas utilizadas no ensino e aprendizagem de matemática de estudantes cegos. Desta forma, procura-se verificar se esses recursos foram concebidos na perspectiva do (DU), bem como se as metodologias indicadas nas pesquisas abordam o DUA.

As buscas pelas produções científicas foram realizadas no site do Programa de PósGraduação em Educação: Teoria e Prática de Ensino (PPGE:TPEn) da Universidade Federal 
do Paraná (UFPR), local em que os autores do presente estudo estão inseridos; e no Catálogo de Teses e Dissertações da Coordenação de Aperfeiçoamento de Pessoal de Nível Superior (CAPES). Buscou-se ainda a pesquisa que deu origem ao material didático Multiplano, amplamente conhecido e utilizado por professores de matemática.

No site do PPGE:TPEn da UFPR foram analisados os títulos de todas as dissertações procurando as que evidenciassem a análise e desenvolvimento de material didático para estudantes cegos, e foi encontrado o trabalho de Berbetz (2019), que apresenta o desenvolvimento, aplicação e avaliação de um material didático.

No Catálogo de Teses e Dissertações da CAPES foram realizadas duas buscas, sendo que na primeira os descritores utilizados foram "material didático", "matemática" e "cego", de forma associada, com o operador booleano $A N D$. Foram encontrados dois trabalhos, e, após a leitura dos títulos e resumos, um deles foi descartado. Desta busca a pesquisa selecionada é a de Vita (2012), na qual a autora avalia a construção e a potencialidade de um material didático, uma maquete tátil, construída a partir de cinco protótipos com vista à apreensão de conceitos básicos de probabilidade com a finalidade de atender os objetivos de aprendizagem de estudantes cegos.

A segunda busca no catálogo CAPES, cujos descritores utilizados foram "tecnologia assistiva", "matemática" e "cego", de forma associada com o operador Booleano AND, resultou na seleção de quatro pesquisas. Ao analisar o título e o resumo dos achados um deles foi descartado por não estar na área de Educação ou Ensino. Após a análise dos títulos e resumos das outras três pesquisas, apenas a de Salvino (2017) foi selecionada, pois apresenta tecnologias assistivas utilizadas durante o processo de ensino da matemática por estudante com cegueira adquirida. Dentre as tecnologias apresentadas, seja para a compreensão de conceitos matemáticos ou operações e cálculos, a autora destaca: o reglete e punção; máquina perkins; impressora braille; linha braille; livro com leitura tátil ou audível; soroban; calculadora sonora.

Quanto ao Multiplano, este recurso foi desenvolvido na prática docente do professor Rubens Ferronato (2002), discutido em sua dissertação de mestrado, que, posteriormente, teve uma versão comercial amplamente difundida. Devido aos benefícios que o Multiplano proporciona para o ensino e aprendizado de matemática, esse é utilizado como recurso educacional para estudantes com deficiências, sobretudo pessoas cegas.

Assim, quatro são as pesquisas stricto sensu analisadas neste estudo: Placas algébricas (BERBETZ, 2019); Multiplano (FERRONATO; 2002); Maquete tátil (VITA, 2012); e as Tecnologias Assistivas citadas por Salvino (2017). 


\section{Resultados e análises}

O recurso utilizado por Berbetz (2019) foi desenvolvido para o ensino de operações com polinômios, surgindo assim as Placas Algébricas (FIGURA 2), inspiradas no Material dourado da educadora Maria Montessori, que desenvolveu materiais manipulativos, destinados à aprendizagem da matemática para crianças.

\section{Figura 2 - Placas algébricas}
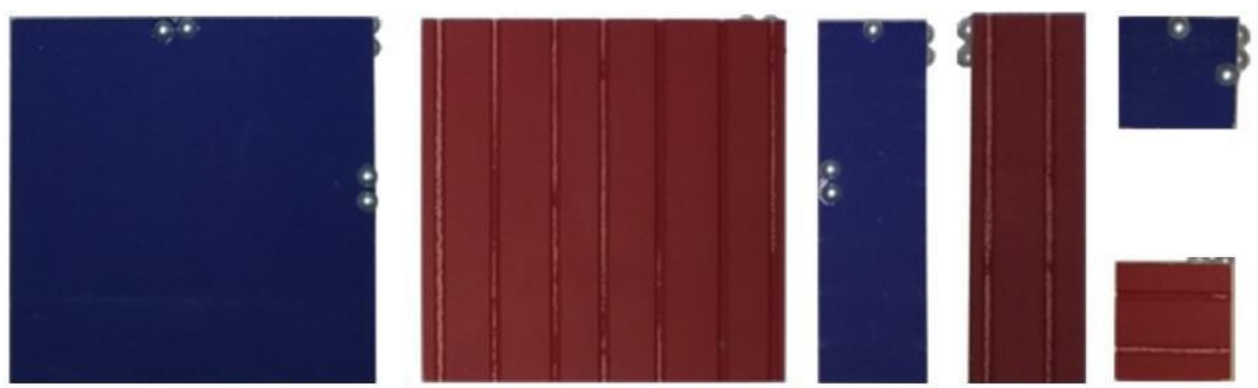

Fonte: Berbetz (2019, p. 63)

A autora indica que o material é composto de seis placas de madeira com os formatos retangular e quadrado, constando código Braille e face com textura, representando placas positivas e placas negativas. Os pontos do Código Braille foram representados por meia pérola de artesanato, indicando as dimensões, comprimento, largura e altura das placas, dimensões variáveis nas atividades propostas. Com isso, o estudante cego pode manipular o material por meio do tato, percebendo a forma, o tamanho, as texturas, construindo imagens mentais resultantes da percepção tátil.

Vita (2012) elaborou uma maquete tátil com o objetivo de promover a compreensão de conceitos de probabilidade por estudantes cegos (FIGURA 3). 
Figura 3 - Maquete tátil

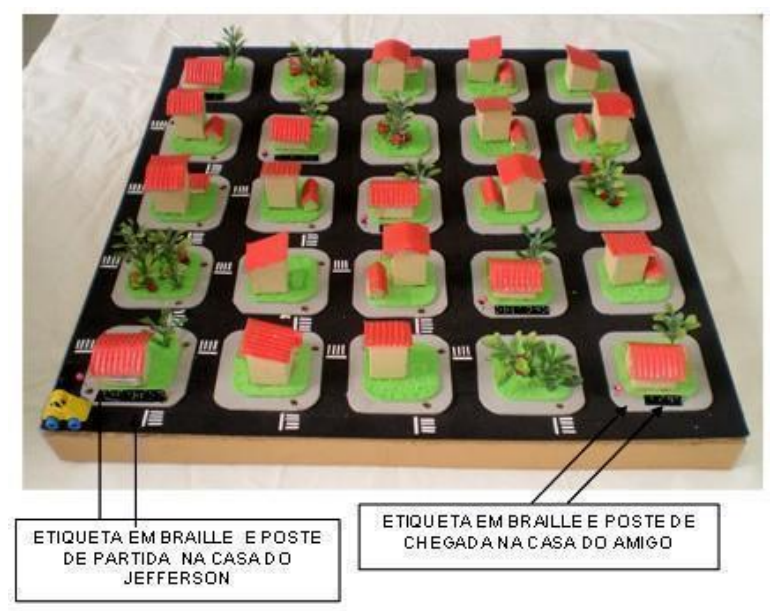

Fonte: Vita (2012, p. 157)

Cada construção seguiu as cinco etapas da Metodologia do Design Centrado no Usuário, processo em que o foco está nas necessidades e limitações dos usuários. A análise instrumental de cada protótipo relacionou quatro polos do modelo das situações de atividades coletivas: aluno cego, maquete tátil, pesquisadores e especialistas. Tais modelos foram adaptados, a partir do modelo de ergonomia, "sobre a interação entre os homens e a tecnologia, adaptando tarefas, sistemas, produtos e ambientes às habilidades e limitações físicas e mentais das pessoas" (VITA, 2012, p. 50).

Salvino (2017) apresenta diversos recursos para auxiliar o ensino e aprendizagem do estudante cego, como: na Figura 4a pode-se observar a "Reglete" e "Punção"; na Figura 4b é apresentada a Máquina Perkins; na Figura 4c pode-se verificar o Soroban; Impressora Braille, Linha/Display Braille, livro com leitura tátil ou audível e calculadora sonora. 
Figura 4 - a) Reglete e Punção, b) Máquina Perkins, c) Soboran

a)
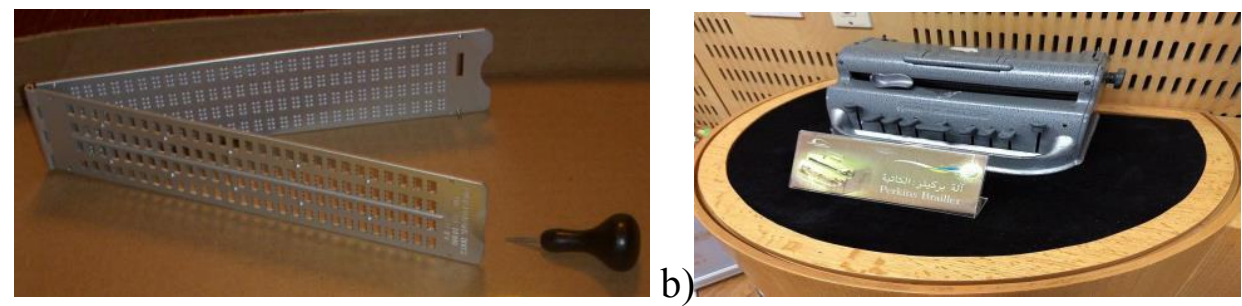

c)

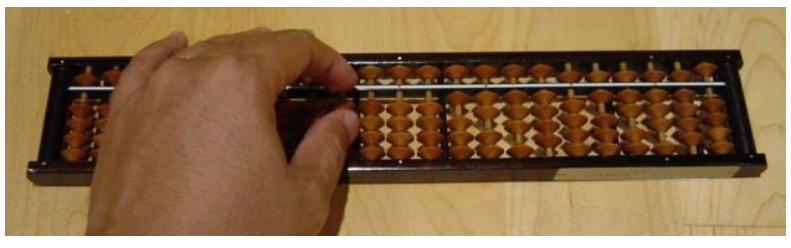

Fonte: Links no rodapé 5

Reglete e Punção têm a função de alfabetizar deficientes visuais e "em nível de instrução tem chances reais de uma progressão real como qualquer outro aluno que use caderno e o lápis para escrever" (SALVINO, 2017, p. 15). A máquina Perkins é uma tecnologia assistiva que facilita a escrita em Braille, reduzindo o esforço e tempo que seria gasto por estudantes cegos na escrita manual. O Soroban tem a função de auxiliar no desenvolvimento de habilidades matemáticas em operações básicas, podendo ser utilizado também por videntes. A Impressora Braille segue a função das impressoras tradicionais, porém, permitindo a impressão dos dois lados do papel, além de desenhos e escrita em braille. A Linha ou Display Braille é um equipamento eletrônico que ao ser conectado em um computador tem a função de fazer a leitura do texto exibido na tela do computador. A autora ainda discute o uso do DOSVOX, sistema computacional que se destina a facilitar o acesso de deficientes visuais por meio da síntese de voz, possibilitando a autonomia aos estudantes.

Ferronato (2002) criou o recurso Multiplano, como pode ser observado na Figura 5, pensando, inicialmente, no estudante cego.

5 a) Disponível em: https://upload.wikimedia.org/wikipedia/commons/e/eb/Slate_and_Stylus_3_cropped.jpg.

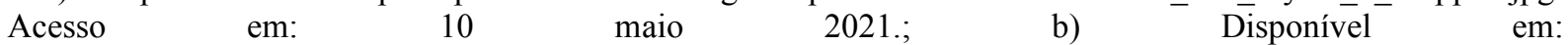
https://upload.wikimedia.org/wikipedia/commons/2/29/Biblioteca_Braille_Taha_Hussein_05.jpg. Acesso em: 10 maio 2021.; c) Disponível em: https://upload.wikimedia.org/wikipedia/commons/7/72/ Soroban.JPG. Acesso em: 10 maio 2021. 
Figura 5 - Versão comercial do Multiplano

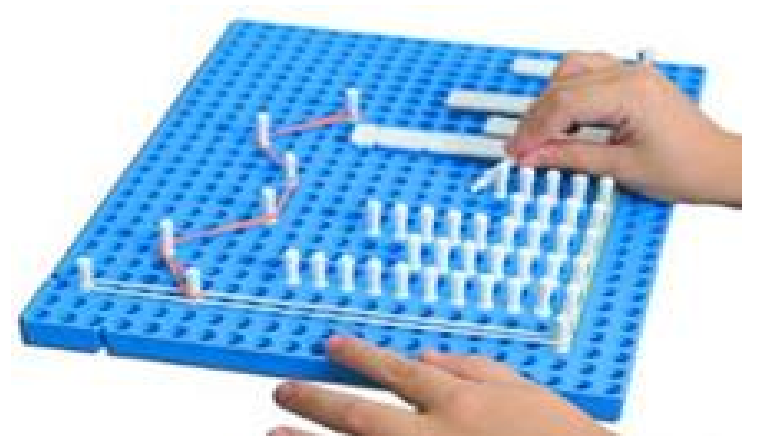

Fonte: Multiplano ${ }^{6}$

O autor explica que no intuito de tornar a disciplina mais próxima da realidade do estudante cego, após várias tentativas de ensino dos conteúdos matemáticos, surgiu a ideia do Multiplano, inicialmente confeccionado com uma placa de madeira com diversas perfurações, comprada em loja de material de construção.

Em uma busca por mais informações sobre o Multiplano, verificamos que em 2018 essa tecnologia assistiva foi aprovada como recurso pedagógico para compor o guia de tecnologias educacionais ${ }^{7}$, atendendo estudantes com diversas dificuldades de aprendizagem relacionadas à Matemática e, também, a alguns conceitos de Física.

Ao relacionar as tecnologias apresentadas nessa seção com o DU é possível verificar que todos possuem tamanhos adequados de mobiliários, permitindo seu manuseio, satisfazendo o princípio abrangente. Ainda, tais recursos didáticos mostram-se seguros, não exigem esforço físico de quem os manuseia e encaixam com facilidade, denotando a ideia de flexibilidade.

Entretanto, os recursos apresentados por Salvino (2017), reglete e punção, máquina Perkins, impressora braille, linha/display braille e livro com leitura tátil são tecnologias assistivas, que não possuem todos os princípios do DU, visto que seu uso se restringe aos estudantes cegos ou por aqueles que compreendem o código Braille. Assim, com exceção dessas tecnologias, as demais permitem a experimentação sem a exigência de conhecimentos prévios para o manuseio, permitindo a exploração tátil da textura em relevo, trazendo informações perceptíveis aos estudantes independentemente de sua idade, remetendo à ideia do óbvio.

${ }^{6}$ Disponível em: http://multiplano.com.br. Acesso em: 10 maio 2021.

${ }^{7}$ Disponível em: https://tecnologiaeducacional.mec.gov.br/assets-plataforma-evidencias/1545309628-Portaria\% 2052.pdf Acesso em: 10 maio 2021. 
O Multiplano, as Placas algébricas, a maquete tátil, o soroban, o livro audível e a calculadora sonora cumprem com todos os princípios do DU. Ainda, o Multiplano e as Placas algébricas, aliadas às metodologias expostas pelas pesquisas, proporcionam o DUA, atendendo os três princípios.

O princípio do engajamento é verificado na pesquisa de Berbetz (2019), quando a autora afirma que essa tecnologia ofereceu oportunidades para que todos os participantes interagissem em diferentes contextos, favorecendo a construção do conhecimento. Tal princípio também é averiguado na pesquisa de Ferronato (2002, p. 74), quando informa que "mesmo alunos cegos, e principalmente eles, puderam participar dos grupos e analisar os resultados de forma efetiva e não como meros espectadores".

As diretrizes do princípio da representação são explicitadas nos comentários de Berbetz (2019) e Ferronato (2000) ao afirmarem que a "abstração de conceitos e propriedades ficam evidentes no momento em que a PQ [pesquisadora] modela as representações para produtos de acordo com as regras de sinais da multiplicação" (BERBETZ, 2019, p. 87) e que o Multiplano "é um recurso que auxilia na abstração e, quando a mesma se efetiva, torna-se dispensável" (FERRONATO, 2000, p. 41).

Quanto ao princípio da ação e expressão, é verificado na interação do estudante cego “com o material sem barreiras, acessando os conhecimentos prévios da propriedade associativa em relação às operações de adição e subtração e, ainda, transformando a informação em conhecimento" (BERBETZ, 2019, p. 82), o que despertou diferentes habilidades intrínsecas do participante. Ferronato corrobora com esse pensamento ao afirmar que "a abstração dos conceitos pode ser facilitada quando se trabalha com o concreto, com o palpável" (FERRONATO, 2000, p. 41).

Constata-se que esses dois recursos didáticos produzidos são materiais manipuláveis, sendo modelos flexíveis de demonstração que permitem fornecer informações sobre aprendizagem dos estudantes em tempo real na prática docente-estudante, demonstrando que os estudantes podem se apropriar dos conceitos matemáticos a partir da manipulação de recursos didáticos concretos, vistos como facilitadores do processo ensino e aprendizagem por meio da mediação dos professores. Assim, é possível afirmar que as atividades propostas promoveram a interação entre os participantes, possibilitando a troca de experiências e a socialização de conhecimento, reforçando que a aprendizagem acontece quando o indivíduo, participante de um grupo social, convive com outras pessoas, provocando trocas de informações (BERBETZ, 2019, p. 74). 
Tais experiências vêm ao encontro da Declaração de Salamanca, que prevê que a aprendizagem deve adaptar-se ao estudante e não o estudante adaptar-se à aprendizagem, efetivando a educação inclusiva como direito que deve atender às especificidades dos estudantes, respeitando os diferentes ritmos de aprendizagens.

Quanto à pesquisa de Vita (2012), o estudo não possui a abordagem DUA, visto que não se encaixa no princípio de engajamento em virtude de ter ocorrido num espaço fora do ambiente da sala regular, sem a participação dos demais estudantes, restringindo a experiência da maquete tátil ao grupo de estudantes da sala de recursos multifuncional. No entanto, a pesquisa é considerada dentro da temática de tecnologia assistiva, pois o produto foi utilizado em prol da autonomia e independência dos estudantes. Da mesma forma, a pesquisa desenvolvida por Salvino (2017) retrata um estudo de caso, que permitiu à autora observar o estudante cego em dois espaços: sala de recursos multifuncional e a sala de aula regular. Embora a autora defenda o uso de tecnologia assistiva, constata-se ao longo do estudo que a escola pesquisada não faz uso de recurso didático para promover a aprendizagem do estudante cego. A autora enfatiza a atenção sobre a necessidade das escolas se prepararem para atender os estudantes de inclusão, buscando formação continuada aos professores. Assim, conclui o estudo reafirmando que "como consequência da negação à deficiência, tem-se a negação à inclusão" (SALVINO, 2017, p. 89).

\section{Considerações Finais}

$\mathrm{O}$ respeito à diversidade no contexto escolar direciona a necessidade de buscar encaminhamentos metodológicos e recursos didáticos que atendam às especificidades de aprendizagem dos estudantes de inclusão em propostas que extrapolam os conceitos préconcebidos e discutem a quebra das barreiras existentes na sala de aula que impedem a compreensão dos conceitos e conteúdos curriculares por muitos estudantes. É necessário pensar sobre estes aspectos, pois somente a inserção dos estudantes com alguma necessidade educacional em salas regulares não garante o acesso à aprendizagem, podendo, por vezes, gerar a segregação, sinalizando para exclusão institucionalizada.

A educação inclusiva vem mostrando avanços, porém ainda tem um caminho a ser percorrido. Desta forma, este estudo analisou pesquisas stricto sensu que apresentaram tecnologias assistivas que são utilizadas por estudantes cegos para o ensino e aprendizagem de matemática. Assim, buscou-se verificar se esses recursos indicados pelas pesquisas estão 
concebidos na perspectiva do Desenho Universal (DU) e, ainda, se as metodologias indicadas nas pesquisas possuem abordagem do Desenho Universal para Aprendizagem (DUA).

Salvino (2017) explicita ser necessário explorar o potencial de aprendizagem dos estudantes, pois as dificuldades de aprendizagem não estão propriamente nos sujeitos, mas muitas vezes, na negação do acesso aos conteúdos por parte dos professores. Para tanto, os professores precisam transformar seu mundo interno e externo para desenhar uma educação fora das linhas tradicionais, transgredindo e remodelando o ensino, vislumbrando ao estudante cego uma visão diferente de mundo com base numa prática pedagógica reflexiva que possibilita um novo modelo de ensinar e de aprender a partir de materiais concretos (SALVINO, 2017). Com isso, é necessário que as escolas se prepararem para atender os estudantes de inclusão, buscando ofertar formação continuada aos professores, orientando sobre a necessidade do uso de tecnologias assistivas que venham ao encontro das demandas de aprendizagem dos estudantes (MANTOAN, 2003). Ainda, compreende-se que para efetivação dessas mudanças há necessidade de mudar o olhar em relação aos estudantes de inclusão, não é bastante a utilização de tecnologias assistivas específicas para o público-alvo, pois, como dito, muitas dessas tecnologias podem, por vezes, proporcionar a segregação. Há que se pensar em tecnologias que atendam a todos os estudantes, por isso, esse estudo buscou apresentar o DU.

A utilização de tecnologias assistivas aliadas com metodologias que abordam o DUA permite o acesso de estudantes aos conteúdos curriculares, ao contrário de materiais para uso exclusivo de um indivíduo, o que o exclui da socialização e da aprendizagem coletiva no ambiente comum de sala de aula. Sobre isso, Bebertz (2019) ressalta que para efetivação do processo de inclusão é fundamental que professores compreendam a função didática de cada material utilizado e proporcione práticas inclusivas com eles. Corroborando com esse pensamento, Ferronato (2002) adverte que o aluno cego precisa de situações adequadas, sem que haja precipitação e impaciência por parte de quem aplica as tarefas, propondo que professores utilizem os mesmos procedimentos, linguagem, cálculos, algoritmos e métodos que usaria no quadro de giz/piloto com os alunos videntes. Reafirmando que "o professor não precisa mudar seus procedimentos quando tem um aluno deficiente visual em sua sala de aula, mas apenas intensificar o uso de materiais concretos" (FERRONATO, 2002, p. 48).

Desta forma, os resultados apresentados nesse estudo nos permitem afirmar que se faz necessária a divulgação do DU e DUA entre os professores dos diversos níveis de ensino, pois essas perspectivas proporcionam a possibilidade do uso de metodologias e da adoção de recursos de tecnologia assistiva que vêm ao encontro das necessidades da educação inclusiva, 
fazendo com que todos os estudantes participem efetivamente dos processos educacionais com equidade no ambiente comum de sala de aula.

\section{REFERÊNCIAS}

BERBETZ, M. R. S. Educação Matemática Inclusiva - O Material Didático na Perspectiva do Desenho Universal para Área Visual. 2019. 148 f. Dissertação (Mestrado em Educação: Teoria e Prática de Ensino, Setor de Educação) - Universidade Federal do Paraná, Curitiba, 2019. Disponível em: https://acervodigital.ufpr.br/handle/1884/66305. Acesso em: 15 fev. 2021.

BRASIL. Lei n. 9.394, de 20 de dezembro de 1996. Lei de Diretrizes e Bases da Educação Nacional. Brasília, DF, 1996. Disponível em:

http://www.planalto.gov.br/ccivil_03/leis/19394.htm. Acesso em: 02 jan. 2021

BRASIL. Lei n. 13.146, de 6 de julho de 2015. Institui a lei brasileira de inclusão da pessoa com deficiência (estatuto da pessoa com deficiência). Brasília, DF, 2015. Disponível em: http://www.planalto.gov.br/ccivil_03/_ato2015-2018/2015/lei/113146.htm. Acesso em: 02 jan. 2021.

CAST. Design for learning guidelines: desenho universal para a aprendizagem.

Massachusetts: CAST Inc., 2011. Disponível em: www.cast.org. Acesso em: 14 jan. 2021.

FERRONATO, R. A. Construção de instrumento de inclusão no Ensino da Matemática. 2002. Dissertação (Mestrado em Engenharia de Produção) - Universidade Federal de Santa Catarina, Florianópolis, 2002.

GABRILLI. M. Guia sobre a Lei Brasileira de Inclusão (LBI). 2016. Disponível em: https://www.maragabrilli.com.br/wp-content/uploads/2016/01/universal_web-1.pdf. Acesso em: 14 fev. 2021.

MANTOAN, M. T. E. Inclusão Escolar: O que é? Por quê? Como fazer? 1. ed. Editora Moderna, 2003.

SALVINO, L. G. M. Tecnologia Assistiva no ensino de Matemática para um aluno cego do Ensino Fundamental: Desafios E Possibilidades. 2017. Dissertação (Mestrado Profissional em Ensino de Ciências e Matemática Instituição de Ensino) - Universidade Estadual da Paraíba, Campina Grande, 2017. Disponível em:

http://tede.bc.uepb.edu.br/jspui/bitstream/tede/2906/2/PDF\%20-\%20Ligiane\%20Go mes\%20 Marinho\%20Salvino.pdf. Acesso em: 15 mar. 2021.

SEBASTIAN-HEREDERO, E. Diretrizes para o Desenho Universal para a Aprendizagem (DUA). Revista Brasileira de Educação Especial, Bauru, v. 26, n. 4, p. 733-768, out. 2020. DOI: https://doi.org/10.1590/1980-54702020v26e0155

UNESCO. Organização das Nações Unidas para a Educação, a Ciência e a Cultura. Declaração de Salamanca e Enquadramento da Acção na área das necessidades 
educativas especiais. Salamanca, Espanha, 1994. Disponível em:

http://portal.mec.gov.br/seesp/arquivos/pdf/salamanca.pdf. Acesso em: 5 abr. 2020.

VITA, A. C. Análise instrumental de uma Maquete Tátil para a Aprendizagem de Probabilidade por alunos cegos. 2012. Tese (Doutorado em Educação Matemática) Pontifícia Universidade Católica de São Paulo, São Paulo, 2012. Disponível em: https://tede.pucsp.br/bitstream/handle/10906/1/Aida\%20Carvalho\%20Vita.pdf Acesso em: 01 mar. 2021.

\section{Como referenciar este artigo}

JEREMIAS, S. M. F.; GÓES, A. R. T.; HARACEMIV, S. M. C. Tecnologias assistivas no ensino e aprendizagem de matemática para estudante cego: investigando a presença do desenho universal e do desenho universal para aprendizagem. Revista Ibero-Americana de Estudos em Educação, Araraquara, v. 16, n. esp. 4, p. 3005-3019, dez. 2021. e-ISSN: 19825587. DOI: https://doi.org/10.21723/riaee.v16iesp.4.16064

Submetido em: 15/10/2021

Revisões requeridas em: 30/10/2021

Aprovado em: $10 / 12 / 2021$

Publicado em: 30/12/2021 